Article

\title{
Fruit Antioxidants during Vinegar Processing: Changes in Content and in Vitro Bio-Accessibility
}

\author{
Sena Bakir ${ }^{1,2}$, Gamze Toydemir ${ }^{3}$, Dilek Boyacioglu ${ }^{1}$, Jules Beekwilder ${ }^{4}$ and Esra Capanoglu ${ }^{1, *}$ \\ 1 Department of Food Engineering, Faculty of Chemical and Metallurgical Engineering, \\ Istanbul Technical University, Maslak, 34469 Istanbul, Turkey; senabakir@gmail.com (S.B.); \\ boyaci@itu.edu.tr (D.B.) \\ 2 Department of Food Engineering, Faculty of Engineering, Recep Tayyip Erdogan University, Merkez, \\ 53100 Rize, Turkey \\ 3 Department of Food Engineering, Faculty of Engineering and Architecture, Okan University, Akfirat-Tuzla, \\ 34959 Istanbul, Turkey; toydemir.gamze@gmail.com \\ 4 Plant Research International, Wageningen UR, 6700 AA Wageningen, The Netherlands; \\ jules.beekwilder@wur.nl \\ * Correspondence: capanogl@itu.edu.tr; Tel.: +90-533-339-7938
}

Academic Editor: Maurizio Battino

Received: 19 August 2016; Accepted: 21 September 2016; Published: 29 September 2016

\begin{abstract}
Background: Vinegars based on fruit juices could conserve part of the health-associated compounds present in the fruits. However, in general very limited knowledge exists on the consequences of vinegar-making on different antioxidant compounds from fruit. In this study vinegars derived from apple and grape are studied. Methods: A number of steps, starting from the fermentation of the fruit juices to the formation of the final vinegars, were studied from an industrial vinegar process. The effect of each of the vinegar processing steps on content of antioxidants, phenolic compounds and flavonoids was studied, by spectroscopic methods and by high-performance liquid chromatography (HPLC). Results: The major observation was that spectrophotometric methods indicate a strong loss of antioxidant phenolic compounds during the transition from fruit wine to fruit vinegar. A targeted HPLC analysis indicates that metabolites such as gallic acid are lost in later stages of the vinegar process. Conclusion: The major conclusion of this work is that major changes occur in phenolic compounds during vinegar making. An untargeted metabolite analysis should be used to reveal these changes in more detail. In addition, the effect of vinegar processing on bio-accessibility of phenolic compounds was investigated by mimicking the digestive tract in an in vitro set up. This study is meant to provide insight into the potential of vinegar as a source of health-related compounds from fruit.
\end{abstract}

Keywords: vinegar; apple; grape; antioxidant; polyphenol

\section{Introduction}

Fruits are known to contain a variety of health-associated compounds [1-7]. Among them are many vitamins and polyphenolic compounds for which part of the health effects have been associated with their antioxidant activity and are therefore referred to as anti-oxidants [8]. When tested in cell free systems or in cultures of cells, antioxidants have the ability to protect molecules such as DNA or cell walls from damage caused by free radical induced oxidative stress [9]. In dietary studies and in vivo experiments using animals, these antioxidants are associated with lower risks of degenerative diseases, particularly cardiovascular diseases and cancer besides inflammatory and neurodegenerative diseases [10-16].

In recent years, the effect of food processing on fruit antioxidants has been investigated [17-23]. Food processing is traditionally used to preserve vitamin sources for consumption during winter, etc. 
In more recent years, fruit juices have been attractive to consumers as a source for intake of beneficial compounds that occur in fruit. In order to evaluate if processed fruit products would provide the same amounts of antioxidant compounds as fresh fruits, changes in content of those antioxidants during processing should be evaluated. Moreover, in recent years it has become clear that antioxidants may differ strongly in their bio-accessibility, i.e., the fraction of each compound that is absorbed by the digestive system and is available in the blood circulation [12].

Vinegar can be made from industrial alcohol, but is often a fermentation product of fruit juices, which contains $5 \%-10 \%$ acetic acid. Turkey is a large producer of such fruit-based vinegars. To produce vinegar from fruit juices, a wine is produced by yeast fermentation, after which the ethanol in the wine is slowly converted to acetic acid by acetic acid bacteria. Vinegar is not only used as an acidic seasoning, but also as a specialty food ingredient, due to proclaimed beneficial effects, such as digestive effects, appetite stimulation, antioxidant effects, exhaustion-recovering effects, lipid lowering effects, and regulations of blood pressure [23,24].

Phenolic compounds in vinegar may derive from the starting material (i.e., the fruit), or may be introduced to it by aging of the vinegar in wooden barrels. Therefore, large differences exist in content of phenolic compounds among vinegars. For example, (+)-Catechin was not found in malt vinegar, while $8.29 \mathrm{mg}(+)$-Catechin per $100 \mathrm{~mL}$ of apple vinegar was observed [25]. In another case, gallic acid was not observed in alcohol vinegar [25], while others reported $9.50 \mathrm{mg} / 100 \mathrm{~mL}$ gallic acid in alcohol vinegar aged in wood [26]. These findings indicate that the polyphenolic composition may differ strongly between vinegars.

The aim of this study was to determine the effect of vinegar processing on content of antioxidants, phenolic compounds and flavonoids, using spectroscopic methods. Different steps of the production process of vinegar were analyzed. In addition, the effect of vinegar processing on bio-accessibility of phenolic compounds was investigated with in vitro methods; in this way we hope to gain insight into the potential of vinegar as a source of health-related compounds.

\section{Results}

\subsection{The Effects of Vinegar Processing on Antioxidant Compounds}

As a first step, dry matter contents of grape and apple vinegar processing samples were measured, to be able to calculate the effects of processing fruit antioxidants on dry weight basis. Dry matter contents of grape and apple vinegar processing samples are given in Table 1. Subsequently, grape vinegar and apple vinegar processing samples were utilized for measuring the effects on total flavonoid content (TFC), total phenolic content (TPC) and total antioxidant capacity (TAC) of samples. Results were determined on a fresh weight basis (FWB), and calculated to dry weight basis (DWB) at tables.

Table 1. The percent dry matter values for the apple and grape vinegar processing samples.

\begin{tabular}{cccc}
\hline \multicolumn{2}{c}{ Apple Vinegar Processing } & \multicolumn{2}{c}{ Grape Vinegar Processing } \\
\hline Samples & \% Dry Matter & Samples & \% Dry Matter \\
\hline AJC & $70.50 \pm 0.01$ & GW & $7.50 \pm 0.01$ \\
AW & $7.50 \pm 0.01$ & RGV & $8.25 \pm 0.01$ \\
CAV & $8.8 \pm 0.1$ & CGV & $7.8 \pm 0.1$ \\
FAV & $7.8 \pm 0.1$ & FGV & $8 \pm 1$ \\
FPAV & $4.3 \pm 0.4$ & FPGV & $3.8 \pm 0.3$ \\
\hline
\end{tabular}

Results are given in percent dry matter. GW is grape wine; RGV is raw grape vinegar (not decanted and not filtered); CGV is clarified grape vinegar; FPGV is final packaged grape vinegar; and FGV is final grape vinegar; AJC is apple juice concentrate; AW is apple wine; CAV is clarified apple vinegar; FPAV is final packaged apple vinegar; FAV is final apple vinegar product. 


\subsubsection{Effects of Vinegar Processing on Grape Antioxidants}

The grape vinegar processing was studied for its effects on TPC, TFC, and TAC of different processing samples including while the samples collected for grape vinegar processing included grape wine (GW), raw grape vinegar (RGV), clarified grape vinegar (CGV), filtered grape vinegar (FGV), and the final packaged grape vinegar (FPGV). The TFC, TPC and TAC values, determined for grape vinegar processing samples, are represented in Table 2 . From grape wine to grape vinegar, samples were not found to be significantly different regarding to their TFC and TPC when the calculations were performed on DWB $(p>0.05)$. Remarkably, samples collected from the intermediary steps of processing were all found to be significantly lower in their TFC and TPC values, in comparison to grape wine sample. The antioxidant capacity (TAC) changed also during the process of vinegar making from wine. Although statistical analysis indicates that changes are significant, the changes in activity were less than a factor 2 .

Table 2. Total flavonoid, phenolic content, and total antioxidant capacity of grape and apple vinegar processing samples.

\begin{tabular}{|c|c|c|c|c|c|c|c|}
\hline \multicolumn{2}{|c|}{ Samples } & \multirow{2}{*}{$\begin{array}{c}\text { TFC }^{\mathbf{x}} \\
145 \pm 7^{\mathrm{a}}\end{array}$} & \multirow{2}{*}{$\begin{array}{c}\text { TPC }^{\mathbf{y}} \\
918 \pm 144^{\text {a }}\end{array}$} & \multirow{2}{*}{$\begin{array}{c}\text { ABTS }^{\mathbf{z}} \\
1495 \pm 328^{\mathrm{a}}\end{array}$} & \multirow{2}{*}{$\begin{array}{c}\text { CUPRAC }^{\mathbf{z}} \\
1577 \pm 182^{\mathrm{b}}\end{array}$} & \multirow{2}{*}{$\begin{array}{c}\text { DPPH }^{\mathbf{z}} \\
1410 \pm 25^{\mathrm{b}}\end{array}$} & \multirow{2}{*}{$\begin{array}{c}\text { FRAP }^{\mathbf{z}} \\
433 \pm 24^{b}\end{array}$} \\
\hline \multirow{5}{*}{$\begin{array}{l}\text { Grape } \\
\text { Vinegar }\end{array}$} & GW & & & & & & \\
\hline & RGV & $79 \pm 30^{b}$ & $676 \pm 69^{b}$ & $1062 \pm 234^{\mathrm{a}}$ & $1138 \pm 206^{c}$ & $902 \pm 31^{c}$ & $341 \pm 14^{\mathrm{c}}$ \\
\hline & CGV & $81 \pm 14^{b}$ & $492 \pm 27^{c}$ & $418 \pm 49^{b}$ & $1024 \pm 99^{c}$ & $870 \pm 44^{c}$ & $293 \pm 23^{c}$ \\
\hline & FGV & $101 \pm 16^{b}$ & $506 \pm 37^{c}$ & $441 \pm 36^{b}$ & $1042 \pm 164^{c}$ & $888 \pm 39^{c}$ & $302 \pm 29^{c}$ \\
\hline & FPGV & $153 \pm 19^{a}$ & $842 \pm 171^{a}$ & $1158 \pm 207^{a, b}$ & $2048 \pm 191^{\mathrm{a}}$ & $1612 \pm 244^{a}$ & $568 \pm 76^{a}$ \\
\hline \multirow{5}{*}{$\begin{array}{c}\text { Apple } \\
\text { Vinegar }\end{array}$} & AJC & $47 \pm 4^{c}$ & $232 \pm 19^{d}$ & $2561 \pm 260^{a}$ & $831 \pm 106^{b}$ & $1470 \pm 74^{\mathrm{a}}$ & $321 \pm 20^{b}$ \\
\hline & $\mathrm{AW}$ & $240 \pm 10^{\mathrm{a}}$ & $519 \pm 55^{\mathrm{a}}$ & $2372 \pm 224^{a}$ & $1602 \pm 124^{a}$ & $1571 \pm 111^{\mathrm{a}}$ & $537 \pm 16^{\mathrm{a}}$ \\
\hline & CAV & $81 \pm 12^{b}$ & $383 \pm 12^{c}$ & $570 \pm 49^{c}$ & $648 \pm 105^{c}$ & $712 \pm 28^{c}$ & $257 \pm 16^{c}$ \\
\hline & FAV & $64 \pm 14^{b}$ & $357 \pm 21^{c}$ & $587 \pm 21^{c}$ & $565 \pm 111^{c}$ & $714 \pm 22^{c}$ & $254 \pm 8^{c}$ \\
\hline & FPAV & $42 \pm 9^{c}$ & $459 \pm 58^{b}$ & $1256 \pm 110^{b}$ & $908 \pm 118^{b}$ & $1087 \pm 149^{b}$ & $323 \pm 31^{b}$ \\
\hline
\end{tabular}

$\mathrm{x}$ : $\mathrm{mg}$ catechin equivalente (CA)/100 mg samples at DWB; ${ }^{\mathrm{y}}: \mathrm{mg}$ gallic acid equivalents (GAE)/100 $\mathrm{mg}$ samples at DWB; ${ }^{\mathrm{z}}$ : mg Trolox equivalent antioxidant capacity (TEAC) $/ 100 \mathrm{~mL}$ at fresh weight basis (FWB). GW is grape wine; RGV is raw grape vinegar (not decanted and not filtered); CGV is clarified grape vinegar; FPGV is final packaged grape vinegar; and FGV is final grape vinegar; AJC is apple juice concentrate; AW is apple wine; CAV is clarified apple vinegar; FPAV is final packaged apple vinegar; FAV is final apple vinegar product; ABTS is 2,2'-azino-bis(3-ethylbenzothiazoline-6-sulphonic acid); CUPRAC is cupric reducing antioxidant capacity; DPPH is 2,2-diphenyl-1-picrylhydrazyl; FRAP is ferric reducing antioxidant power. Different lowercase letters $(\mathrm{a}, \mathrm{b}, \mathrm{c}$ and $\mathrm{d})$ indicate statistically significant difference $(p<0.05)$.

\subsubsection{Effects of Vinegar Processing on Apple Antioxidants}

The effects of apple vinegar processing on TPC, TFC, and TAC of several processing samples was also studied. Samples include apple juice concentrate (AJC), apple wine (AW), clarified apple vinegar $(\mathrm{CAV})$, filtered apple vinegar (FAV), and the final packaged apple vinegar (FPAV).

TFC, TPC and TAC of the samples are given together at Table 2. The process from apple juice concentrate to apple wine is associated with an increase in TFC and TPC. Antioxidant capacity of the samples measured with 2,2'-azino-bis(3-ethylbenzothiazoline-6-sulphonic acid) (ABTS), cupric reducing antioxidant capacity (CUPRAC), 2,2-diphenyl-1-picrylhydrazyl (DPPH) and ferric reducing antioxidant power (FRAP) showed variable results. All TAC methods show that there is a loss of TAC going from wine to vinegar in the process.

\subsubsection{The Effects of Vinegar Processing on Phenolic Profile}

Processing effect of vinegar making on phenolic compounds were quantified using HPLC. Phenolic compounds of the grape vinegar samples were measured with HPLC-PDA and quantified (Table 3). Grape wine is rich in gallic acid, however $p$-hydroxybenzoic acid was not observed. After decantation and filtering, the gallic acid concentration sharply decreased more that 10-fold, while $p$-hydroxybenzoic acid was not detected in grape wine and raw grape vinegar, but was observed in the processing products after decantation. 
Table 3. Phenolic acid profiles of the grape and apple vinegar processing samples.

\begin{tabular}{|c|c|c|c|c|c|c|c|}
\hline \multicolumn{2}{|c|}{ Samples } & $\begin{array}{l}\text { Gallic } \\
\text { Acid }\end{array}$ & $\begin{array}{c}p \text {-Hydroxybenzoic } \\
\text { Acid }\end{array}$ & Catechin & $\begin{array}{l}\text { Syringic } \\
\text { Acid }\end{array}$ & $\begin{array}{l}\text { Caffeic } \\
\text { Acid }\end{array}$ & $\begin{array}{c}p \text {-Coumaric } \\
\text { Acid }\end{array}$ \\
\hline \multirow{5}{*}{$\begin{array}{l}\text { Grape } \\
\text { Vinegar }\end{array}$} & GW & $67 \pm 24$ & N.D. & N.D. & N.D. & N.D. & N.D. \\
\hline & RGV & $63 \pm 1$ & N.D. & N.D. & N.D. & N.D. & N.D. \\
\hline & DGV & $5 \pm 2$ & $1.1 \pm 0.5$ & N.D. & N.D. & N.D. & N.D. \\
\hline & DFGV & $5 \pm 2$ & $1 \pm 1$ & N.D. & N.D. & N.D. & N.D. \\
\hline & FGV & $6 \pm 2$ & $0.90 \pm 0.05$ & N.D. & N.D. & N.D. & N.D. \\
\hline \multirow{5}{*}{$\begin{array}{l}\text { Apple } \\
\text { Vinegar }\end{array}$} & AJC & $1.0 \pm 0.1$ & $1.8 \pm 0.1$ & $70 \pm 5$ & $5.2 \pm 0.3$ & $10.3 \pm 0.1$ & $2.0 \pm 0.1$ \\
\hline & $\mathrm{AW}$ & $0.22 \pm 0.02$ & $0.20 \pm 0.02$ & $16 \pm 1$ & $0.48 \pm 0.03$ & $2.3 \pm 0.1$ & $0.30 \pm 0.01$ \\
\hline & DAV & $1.8 \pm 0.1$ & $1.1 \pm 0.3$ & $7.4 \pm 0.2$ & $0.4 \pm 0.1$ & $1.12 \pm 0.04$ & $0.20 \pm 0.02$ \\
\hline & DFAV & $5.2 \pm 0.1$ & $1.2 \pm 0.1$ & $2.8 \pm 0.3$ & $0.20 \pm 0.01$ & $0.52 \pm 0.01$ & $0.11 \pm 0.01$ \\
\hline & FAV & $0.8 \pm 0.4$ & $0.2 \pm 0.1$ & $2.4 \pm 0.1$ & $0.12 \pm 0.02$ & $0.40 \pm 0.01$ & $0.08 \pm 0.01$ \\
\hline
\end{tabular}

Results are given in $\mathrm{mg} / 100 \mathrm{~mL}$ sample. N.D.: Not detected; GW is grape wine; RGV is raw grape vinegar (not decanted and not filtered); DGV is decanted grape vinegar; DFGV is decanted and filtered grape vinegar; and FGV is final grape vinegar; AJC is apple juice concentrate; AW is apple wine; DAV is decanted apple vinegar; DFAV is decanted and filtered apple vinegar; FAV is final apple vinegar product.

Apple vinegar contains a more complex phenolic compound profile. Apart from gallic acid and $p$-hydroxybenzoic acid, also catechin, syringic acid, caffeic acid and $p$-coumaric acid were observed. Most remarkable value was observed at catechin concentration in AJC with $70.30 \pm 4.90 \mathrm{mg} / 100 \mathrm{~mL}$ FW. The concentration of syringic acid, caffeic acid and $p$-coumaric acid declined strongly (4-10-fold) after the processing of apple juice concentrate to apple wine, while gallic acid and $p$-hydroxybenzoic acid did not show this effect.

\subsection{The Effects of in Vitro Digestion on Vinegar Antioxidant Bio-Availability}

A method for investigating in vitro bio-accessibility as described by McDougall [27] was applied to vinegars. Vinegars ("Initial" samples) were subjected to a gastric treatment (PG samples), after which serum available material (IN-samples) and material remaining in the intestinal lumen (OUT-samples) were obtained. For a detailed description see Section 4.3. On these materials, again all spectroscopic analyses-TFC, TPC and TAC—were performed (Table 4).

\subsubsection{The Effects of in Vitro Digestion on Grape Vinegar}

Grape vinegar's PG, IN and OUT fractions were analyzed. Modest and insignificant effects on total phenolic content (TPC) were observed (Table 4). Apparently the compounds measured in this way are not partitioned by the in vitro digestion system. The total flavonoid content (TFC) clearly dropped in the IN samples, indicating that the compounds addressed by the TFC measurements are poorly serum-available. The antioxidant capacity (TAC), addressed by different methods, showed in each methodology that the transition from initial to post-gastric fraction, and in the transition from post-gastric to serum available and non-serum available material, significant losses of activity can be observed. The recovery of antioxidants, representing the serum-available fraction of the initial material, is $10 \%$ to $40 \%$, depending on the analytical method used.

\subsubsection{The Effects of in Vitro Digestion on Apple Vinegar}

Similar to grape vinegar, apple vinegar showed losses of antioxidant activities during in vitro digestion, ranging from $11 \%$ to $44 \%$ recovery in the serum available fraction (IN), depending on the used method. 
Table 4. Total flavonoid, phenolic content, and total antioxidant capacity of in vitro digested grape and apple vinegars.

\begin{tabular}{cccccccc}
\hline \multicolumn{2}{c}{ Samples } & TFC & TPC $^{* *}$ & ABTS $^{* * *}$ & CUPRAC $^{* * *}$ & DPPH $^{* * *}$ & FRAP *** $^{*}$ \\
\hline \multirow{4}{*}{ Grape } & INITIAL & $5.5 \pm 0.1^{\mathrm{a}}$ & $26 \pm 1^{\mathrm{a}}$ & $56 \pm 6^{\mathrm{a}}$ & $58 \pm 11^{\mathrm{a}}$ & $28 \pm 3^{\mathrm{a}}$ & $42 \pm 4^{\mathrm{a}}$ \\
Vinegar & PG & $4.6 \pm 0.2^{\mathrm{b}}$ & $25 \pm 4^{\mathrm{a}}$ & $31.3 \pm 0.3^{\mathrm{b}}$ & $46 \pm 7^{\mathrm{b}}$ & $10 \pm 2^{\mathrm{b}}$ & $24 \pm 1^{\mathrm{b}}$ \\
& IN & $2.05 \pm 0.07^{\mathrm{c}}$ & $22 \pm 5^{\mathrm{a}}$ & $6 \pm 1^{\mathrm{c}}$ & $23 \pm 3^{\mathrm{c}}$ & $5 \pm 1^{\mathrm{c}}$ & $5 \pm 1^{\mathrm{d}}$ \\
& OUT & $4.0 \pm 0.2^{\mathrm{c}}$ & $22 \pm 3^{\mathrm{a}}$ & $7.5 \pm 0.4^{\mathrm{c}}$ & $25 \pm 4^{\mathrm{c}}$ & $6 \pm 2^{\mathrm{c}}$ & $15 \pm 1^{\mathrm{c}}$ \\
\cline { 2 - 8 } & Recovery $\%$ & 37.1 & 83.6 & 10.6 & 39.6 & 18.5 & 12.5 \\
\hline \multirow{5}{*}{ Apple } & INITIAL & $2 \pm 1^{\mathrm{b}}$ & $17 \pm 1^{\mathrm{a}}$ & $37 \pm 7^{\mathrm{a}}$ & $48 \pm 8^{\mathrm{a}}$ & $13 \pm 1^{\mathrm{a}}$ & $30 \pm 4^{\mathrm{a}}$ \\
Vinegar & PG & $3.7 \pm 0.2^{\mathrm{a}}$ & $13 \pm 2^{\mathrm{b}}$ & $24 \pm 1^{\mathrm{b}}$ & $29 \pm 3^{\mathrm{b}}$ & $7 \pm 4^{\mathrm{b}}$ & $13 \pm 2^{\mathrm{b}}$ \\
& IN & $2.4 \pm 0.2^{\mathrm{b}}$ & $12 \pm 2^{\mathrm{b}}$ & $8 \pm 2^{\mathrm{c}}$ & $21 \pm 2^{\mathrm{c}}$ & $3 \pm 1^{\mathrm{c}}$ & $3 \pm 1^{\mathrm{c}}$ \\
& OUT & $2.9 \pm 0.3^{\mathrm{b}}$ & $16 \pm 4^{\mathrm{a}, \mathrm{b}}$ & $5.9 \pm 0.4^{\mathrm{c}}$ & $15 \pm 5^{\mathrm{c}}$ & $5 \pm 2^{\mathrm{b}, \mathrm{c}}$ & $5 \pm 1^{\mathrm{c}}$ \\
\cline { 2 - 8 } & Recovery $\%$ & 100.8 & 73.8 & 21.6 & 43.6 & 23.0 & 11.3 \\
\hline
\end{tabular}

*: mg CA/100 mL sample; **: mg GAE/100 mL sample; ***: mg TEAC/100 mL sample. GW is Grape wine; RGV is raw grape vinegar (not decanted and not filtered); DGV is decanted grape vinegar; DFGV is decanted and filtered grape vinegar; and FGV is final grape vinegar; AJC is apple juice concentrate; AW is apple wine; DAV is decanted apple vinegar; DFAV is decanted and filtered apple vinegar; FAV is final apple vinegar product; PG is post gastric solution; IN is solution inside the dialysis tube; OUT is solution outside the dialysis tube. Different lowercase letters $(\mathrm{a}, \mathrm{b}, \mathrm{c}$ and $\mathrm{d})$ indicate statistically significant difference $(p<0.05)$.

\subsubsection{The Effects of in Vitro Bio-Accessibility on Vinegar Phenolic Profile}

When gallic acid and $p$-hydroxybenzoic acid were followed during in vitro digestion using high-performance liquid chromatography (HPLC), losses and low recovery numbers were obtained: in particular $p$-hydroxybenzoic acid is recovered to less than $10 \%$. Gallic acid is recovered slightly better, but still with $<20 \%$ efficiency (Table 5). Both gastric treatment (PG vs. initial) and pancreatic treatment (IN and OUT vs. PG) have a strong effect, while IN and OUT show similar numbers, indicating that both compounds diffuse freely over the membrane. Numbers are rather similar for both types of vinegar, indicating that the matrix of these compounds has a limited effect on their in vitro bioaccessibility.

Table 5. The phenolic acid profiles of the in vitro digested grape and apple vinegars.

\begin{tabular}{cccc}
\hline Samples & & Gallic Acid & $p$-Hydroxybenzoic Acid \\
\hline & INITIAL & $5.2 \pm 0.2 *$ & $0.45 \pm 0.01$ \\
Grape Vinegar & PG & $1.63 \pm 0.01$ & $0.1 \pm 0.1$ \\
& IN & $0.66 \pm 0.01$ & $0.03 \pm 0.01$ \\
& OUT & $0.77 \pm 0.04$ & $0.010 \pm 0.001$ \\
\cline { 2 - 4 } & Recovery \% & 12.8 & 6.7 \\
\hline \multirow{5}{*}{ Apple Vinegar } & INITIAL & $0.92 \pm 0.05$ & $0.34 \pm 0.05$ \\
& PG & $0.31 \pm 0.01$ & $0.09 \pm 0.01$ \\
& IN & $0.18 \pm 0.01$ & $0.03 \pm 0.01$ \\
& OUT & $0.21 \pm 0.01$ & $0.02 \pm 0.01$ \\
\cline { 2 - 4 } & Recovery \% & 19.6 & 8.8 \\
\hline & * Results are given in $\mathrm{mg} / 100 \mathrm{~mL}$ sample. &
\end{tabular}

\section{Discussion}

This study was meant to provide an initial view on processes occurring during vinegar-making, from the perspective of phenolic antioxidants. Two different sorts of analytical methodology were tested: a number of spectroscopic assays, which are aimed to provide a more global impression of effects on phenolic compounds, and a dedicated HPLC method, which is largely focused on specific phenolic compounds which are known to occur in vinegar.

The outcome from this study is that the spectroscopic studies are not straightforward to interpret. For example, some antioxidant activity assays like the ABTS assay show almost no change in value 
between apple juice concentrate and apple wine samples (Table 2), while the CUPRAC method for measuring antioxidant activity reports an almost 2-fold increase in activity in the apple wine samples, compared to the juice. Each of these methods measures a different aspect of antioxidant activity, but could, for example, also respond differently to acidity values or ethanol content of samples [28], and thus change values irrespective of the content of phenolic compounds. Niki [29] also points out that the capacity of free radical scavenging does not always correlate well with the capacity to inhibit oxidation. The dedicated method is much more accurate, in that it is much less sensitive to the matrix of the specific phenolic compounds, while a drawback of this method is that it only focusses on a few compounds, while compounds may undergo a transition during the making of vinegar (polymerization, partial oxidation) which not necessarily completely abolishes their relevant bioactivity. For example, this can be observed in the occurrence of $p$-hydroxybenzoic acid in grape vinegar only after the decanting of vinegar, while the gallic acid content of vinegar sharply declines after decantation. Given the highly related structure of both compounds, one could expect that $p$-hydroxybenzoic acid is formed along similar lines as gallic acid, for example by oxidation of more complex, possibly polymeric phenolic compounds [30]. Therefore both methods have their virtues and their drawbacks. More comprehensive analysis of the metabolite changes during fruit processing, using untargeted HPLC methods coupled to mass spectrometry (HPLC-MS), has been performed for the processing of tomato fruit to tomato paste [17], and for the processing of sour cherry fruit to fruit juice [20]. Given the great changes observed for the phenolic compounds identified in grape and apple vinegar (Table 3), such an untargeted HPLC-MS analysis would reveal many more changes than are now already disclosed by the dedicated HPLC analysis.

A number of studies have described the antioxidant properties of vinegars [26,31-33]. A more detailed analysis was presented by Ubeda et al. [34], who focused on the effect of different processing techniques on antioxidant activity and total phenols during a laboratory production of persimmon vinegars. In their analysis, hardly any changes were observed in antioxidant activity during vinegar production. This contrasts with the findings in our study on commercial apple- and grape-vinegar production (Table 1), where, depending on the method used, loss of antioxidant capacity up to a factor 2 is observed.

Cerezo et al. [35] studied the anthocyanin composition and antioxidant activity of Cabernet Sauvignon red wine vinegar produced by submerged acidification in wood. Antioxidant activity of wine and vinegar was determined as $11.23 \pm 0.11$ and $9.61 \pm 0.20 \mathrm{mM}$ Trolox equivalent antioxidant capacity (TEAC)/g sample extract for FRAP essay, $12.26 \pm 0.18$ and $10.2 \pm 0.3 \mathrm{mM}$ TEAC/g sample extract for DPPH essay. A decrease in antioxidant values from wine to vinegar by $14.4 \%, 16.8 \%$ for FRAP and DPPH tests was observed. These losses in antioxidant values from wine to vinegar are slightly lower than those observed in our study. This difference is possibly due to utilization of different red grape varieties, and the use of wooden barrels for vinegar production.

The bio-accessibility of phenolic antioxidants from vinegar is a matter of great interest, and in this work we try to develop methods to address it. From previous studies it has become clear that the presence of matrix compounds such as glucose and citric acid can have a major impact on the passage of polyphenols over intestinal epithelial cells $[27,36]$ and in an in vitro gastrointestinal system such as the system described in this work [21]. In addition to these, bioavailability of antioxidants depends on several factors such as the antioxidant related factors (i.e., chemical structure, molecular linkage), the food matrix and the processing method used, which need further research [37]. In follow-up research of the work on vinegars, the effect of matrix compounds such as acetic acid on the bio-accessibility of vinegar phenolic compounds like gallic acid should be studied. 


\section{Materials and Methods}

\subsection{Vinegar Samples}

The vinegar processing samples from apples (Malus domestica) and grapes (Vitis vinifera) were supplied by the Kühne Turkey Vinegar Factory (İzmir, Turkey), from at least three independent samplings. In processing of both types of vinegar, the fruit juice concentrate, of the respective vinegars, with an average of $60 \%-70 \%$ dry matter content, is first subjected to an alcoholic fermentation, via the use of yeast (Saccharomyces cerevisiae), until the ethyl alcohol content reaches to $8 \%-12 \%(v / v)$ for grape and $9 \%-11 \%(v / v)$ for apple, and this intermediary product is termed as "wine". Subsequently, the acetous fermentation of ethanol into acetic acid takes place with the use of acetic acid bacteria, and the resulting product, with an acetic acid concentration of $\approx 10 \%$, is called as "raw vinegar". Raw vinegar was stored for 3 months, in resin-coated polyester tanks, which provides maturation for the development of the acceptable aroma and quality. When maturation is completed, clarification process takes place by application of bentonite, kieselghur and gelatin for 1-2 days. Following the clarification step, filtration step is carried out, for $4 \mathrm{~h}$, in which the cross-flow microfiltration is applied with the use of ceramic membranes with a pore size of $0.2 \mu \mathrm{m}$. This "filtered vinegar" with an acetic acid concentration of $10 \%$ is diluted to an acid concentration of $4 \%$ by adding water at packaging step. At this packaging step, the vinegar is lastly supplemented with 1-2 mg of sodium metabisulfite in order to get the "final vinegar" product.

Apple and grape vinegar processing samples were collected from different steps of above-mentioned vinegar processing protocol. The samples collected for apple vinegar processing were "apple juice concentrate" (AJC), "apple wine" (AW), "clarified apple vinegar" (CAV), "filtered apple vinegar" (FAV), and the "final packaged apple vinegar" (FPAV); while the samples collected for grape vinegar processing included "grape wine" (GW), "raw grape vinegar" (RGV), clarified grape vinegar" (CGV), "filtered grape vinegar" (FGV), and the "final packaged grape vinegar" (FPGV). Samples were stored at room temperature and just before analysis, all vinegar samples were centrifuged at $2700 \times g$ for 4 min to eliminate the haze-causing compounds. Experiments were performed in triplicate and the results were given as the mean values \pm standard deviations for these triplicate measurements.

\subsection{Dry Matter Content}

Vinegar processing samples were analysed for their Brix values, using an Abbemat Refractometer (Anton Paar, Graz, Austria) at room temperature, in order for the conversion of fresh-weight basis results to dry-weight basis results.

\subsection{In Vitro Bioaccessibility Method}

The in vitro bioaccessibility method was adapted from a study of McDougall et al. [27]. The preparation steps include firstly a solution of $0.05 \mathrm{~g}$ pepsin in $50 \mathrm{~mL}$ of $0.1 \mathrm{M}$ of $\mathrm{HCl}$. Approximately $37.5 \mathrm{~mL}$ of this solvent was taken into a flask and $1 \mathrm{~g} \mathrm{NaCl}$ was added and total volume was adjusted to $500 \mathrm{~mL}$ with distilled water, in order to prepare stomach solvent. For preparing small intestinal media, $10.5 \mathrm{~g}$ of $\mathrm{NaHCO}_{3}$ was adjusted $250 \mathrm{~mL}$ with distilled water. $20 \mathrm{~mL}$ of this solution was taken into a dialysis bag of $20 \mathrm{~cm}$ length and both its ends were closed. Finally, $0.1 \mathrm{~g}$ of pancreatin and $0.625 \mathrm{~g}$ of bile salt were dissolved in $25 \mathrm{~mL}$ distilled water separately and then mixed with each other, and used as pancreatin-bile salts mixture.

To mimic the digestive system, approximately $5 \mathrm{~mL}$ of samples were taken into a $250 \mathrm{~mL}$ beaker. The total volume was adjusted to $20 \mathrm{~mL}$ with stomach solution. Mixture was shaken for homogenous dispersion for $10 \mathrm{~s}$, and $\mathrm{pH}$ was set to $2.0 \pm 0.5$ with $5 \mathrm{~N} \mathrm{HCl}$. Subsequently, samples were placed into shaker water bath for $2 \mathrm{~h}$ and $100 \mathrm{rpm}$ at $37{ }^{\circ} \mathrm{C}$ and at the end of this period, $2 \mathrm{~mL}$ of the material was taken from the beaker as "Post Gastric Solutin (PG)". The $\mathrm{NaHCO}_{3}$ dialysis bag was put into the beaker with the remaining post-gastric solution and $4.5 \mathrm{~mL}$ of pancreatin-bile salt mixture was added. The beaker was placed into the shaker water bath for $2 \mathrm{~h}$ at $37^{\circ} \mathrm{C}$ again. After this step, a sample 
was drawn from inside the dialysis bag, and was called as "IN fraction", and a sample taken outside the dialysis bag was called as "OUT fraction". Those fractions were taken into eppendorf tubes and centrifuged at $14,000 \times g, 4{ }^{\circ} \mathrm{C}$.

\subsection{Determination of Total Phenolic and Flavonoid Content of Vinegars}

\subsubsection{Total Phenolic Content}

Total phenolic content (TPC) of samples was measured based on Folin-Ciocalteu method [38]. Briefly, $100 \mu \mathrm{L}$ of sample was put into an analyis tube and $900 \mu \mathrm{L}$ water was added. Subsequently $5 \mathrm{~mL}$ of $0.2 \mathrm{~N}$ of Folin-Ciocalteau reagent was added and incubated for $3 \mathrm{~min}$. Then, $4 \mathrm{~mL}$ of saturated $\mathrm{Na}_{2} \mathrm{CO}_{3}$ solvent was added and the mixture was incubated for $90 \mathrm{~min}$. At the end of this period absorbance was measured at $765 \mathrm{~nm}$ against a blank by using a spectrophotometer (Shimadzu UV-1700; Shimadzu Corporation, Kyoto, Japan). Gallic acid, $0.01-0.6 \mathrm{mg} / \mathrm{mL}$ in $75 \% \mathrm{MeOH}$, was used for generating the standard curve.

\subsubsection{Total Flavonoid Content}

Total flavonoid content (TFC) was determined based on [39]. In brief, $250 \mu \mathrm{L}$ of sample was taken into an analysis tube and $1.25 \mathrm{~mL}$ distilled water was added to sample. Afterwards, $75 \mu \mathrm{L}$ of $5 \% \mathrm{NaNO}_{2}$ solvent was added and the mixture was kept for $6 \mathrm{~min}$, then $150 \mu \mathrm{L}$ of $10 \% \mathrm{AlCl}_{3} \cdot 6 \mathrm{H}_{2} \mathrm{O}$ solution was added. After $5 \mathrm{~min}, 0.5 \mathrm{~mL}$ of $1 \mathrm{M} \mathrm{NaOH}$ was added and the total volume was adjusted to $2.5 \mathrm{~mL}$ with distilled water. Absorbance was measured at $510 \mathrm{~nm}$ wavelength against a blank. Experiments were conducted in triplicate and mean values were reported. Catechin, $0.01-0.5 \mathrm{mg} / \mathrm{mL}$ in $75 \% \mathrm{MeOH}$, was used for generating the standard curve.

\subsection{Determination of Total Antioxidant Capacity}

Measurements of total antioxidant capacity (TAC) of vinegar samples were performed using four different methods, which are generally used for fruits and vegetables. Experiments were conducted in triplicate and mean values were reported. Trolox (6-hydroxy-2,5,7,8-tetramethylchroman-2-carboxylic acid), $0.01-0.8 \mathrm{mg} / \mathrm{mL}$ in $75 \% \mathrm{MeOH}$, was used for the standard curve.

\subsubsection{2,2'-Azino-bis(3-ethylbenzothiazoline-6-sulphonic acid) (ABTS) Method}

The ABTS method used was based on [40]. Briefly, $220 \mathrm{mg}$ of 2,2'-azino-bis(3-ethylbenzothiazoline6-sulphonic acid) (ABTS•) was dissolved in $200 \mathrm{~mL}$ of distilled water and $38 \mathrm{mg}$ of $\mathrm{K}_{2} \mathrm{~S}_{2} \mathrm{O}_{8}$ was dissolved in $2 \mathrm{~mL}$ of distilled water. These solutions were mixed and stored overnight in the dark to complete the radicalization. After this process, ABTS• solution was obtained. ABTS• solution was diluted with $0.05 \mathrm{M} \mathrm{KPi}$ buffer $(\mathrm{pH}=8)$ until its absorbance reached to the values of $0.9 \pm 0.2$ at $734 \mathrm{~nm}$. Approximately $100 \mu \mathrm{L}$ of sample was taken into an analysis tube and $1 \mathrm{~mL}$ of ABTS• solution was added to sample with the mixture was vortexed for $15 \mathrm{~s}$. Absorbance was measured after $45 \mathrm{~s}$ at $734 \mathrm{~nm}$ wavelength against water.

\subsubsection{DPPH Method}

The 2,2-diphenyl-1-picrylhydrazyl (DPPH) method was based on [41]. In brief, $2 \mathrm{~mL}$ of $0.1 \mathrm{mM}$ DPPH was mixed with $100 \mu \mathrm{L}$ of sample in a test tube. Samples were stored in the dark at room temperature for $30 \mathrm{~min}$. Absorbance was measured at $517 \mathrm{~nm}$ against methanol.

\subsubsection{Cupric Reducing Antioxidant Capacity (CUPRAC) Method}

The cupric reducing antioxidant capacity (CUPRAC) method was based on [42]. Briefly, $0.4262 \mathrm{~g}$ of $\mathrm{CuCl}_{2} \cdot 2 \mathrm{H}_{2} \mathrm{O}$ was dissolved in $250 \mathrm{~mL}$ of distilled water, $19.27 \mathrm{~g}$ of $\mathrm{NH}_{4} \mathrm{Ac}$ was diluted in $250 \mathrm{~mL}$ of distilled water, and $0.039 \mathrm{~g}$ of Neocuproine was dissolved in $96 \% \mathrm{EtOH}$ and diluted to $25 \mathrm{~mL}$. Approximately $100 \mu \mathrm{L}$ of sample was taken into an analysis tube and $1 \mathrm{~mL}$ of $\mathrm{CuCl}_{2} \cdot 2 \mathrm{H}_{2} \mathrm{O}$ solvent, 
$1 \mathrm{~mL}$ of Neocuproine, $1 \mathrm{~mL}$ of $\mathrm{NH}_{4}$ Ac buffer and $1 \mathrm{~mL}$ of distilled water were added sequentially. After incubating the mixture for $30 \mathrm{~min}$, absorbance was measured at $450 \mathrm{~nm}$ against a blank.

\subsubsection{Ferric Reducing Antioxidant Power (FRAP) Method}

The ferric reducing antioxidant power (FRAP) method was adapted from [43]. Briefly, $3.1 \mathrm{~g}$ of $\mathrm{CH}_{3} \mathrm{COONa} \cdot 3 \mathrm{H}_{2} \mathrm{O}$ was dissolved in distilled water, $16 \mathrm{~mL}$ of $99.85 \%$ acetic acid was added and the total volume was adjusted to $1 \mathrm{~L}$ with distilled water. $0.504 \mathrm{~g}$ of $\mathrm{FeCl}_{3} \cdot 6 \mathrm{H}_{2} \mathrm{O}$ was dissolved in distilled water and mixed with $1 \mathrm{M} \mathrm{HCl}$. The total volume of the mixture was adjusted to $100 \mathrm{~mL}$ with distilled water. $0.156 \mathrm{~g}$ of tripyridyl triazine (TPTZ) was dissolved in $50 \mathrm{~mL}$ ethanol. FRAP reagent was prepared with 10:1:1 volume rate with these solution sequence. Afterwards, $100 \mu \mathrm{L}$ of sample was taken into a test tube and $900 \mu \mathrm{L}$ of FRAP reagent was added. After keeping the mixture for $4 \mathrm{~min}$ at room temperature, absorbance was measured at $593 \mathrm{~nm}$ against distilled water.

\subsection{HPLC Analysis of Vinegar Phenolic Profile}

Phenolic profiles of all samples were also evaluated by HPLC coupled to a photodiode array (HPLC-PDA). Phenolic compounds that have been reported in vinegars, such as gallic acid, protocatechuic acid, $p$-hydroxybenzoic acid, (+)-catechin, syringic acid, caffeic acid, $p$-coumaric acid, were determined [44-47]. HPLC-PDA results of samples were given as $\mathrm{mg} / 100 \mathrm{~mL}$ samples for all. HPLC analysis were carried out by using the method adapted from [10]. Standard calibration curves were prepared by using gallic acid, protocatechuic acid, pHBA( $p$-hydroxy benzoic acid), caffeic acid, vanilic acid, (+)-catechin, $p$-coumaric acid and syringic acid. These samples and stock solutions were filtered through a $0.45-\mu \mathrm{m}$ membrane filter and $1 \mathrm{~mL}$ of the filtered sample was placed into vials and analyzed in a Waters W600 HPLC system with PDA (Waters 996) detector, for each sample. Luna C18 column (Phenomenex, Utrecht, The Netherlands), heated to $40^{\circ} \mathrm{C}$, was used as the stationary phase.

The mobile phase included solvent A (distilled water with $0.1 \%(v / v)$ trifluoric acid (TFA)) and solvent B (acetonitrile with $0.1 \%(v / v)$ TFA), acetonitrile with $0.1 \%(v / v)$ TFA. A linear gradient was used as follows: at $0 \mathrm{~min}, 95 \%$ solvent $\mathrm{A}$ and $5 \%$ solvent $\mathrm{B}$; at $45 \mathrm{~min}, 65 \%$ solvent $\mathrm{A}$ and $35 \%$ solvent $\mathrm{B}$; at $47 \mathrm{~min}, 25 \%$ solvent $\mathrm{A}$ and $75 \%$ solvent $\mathrm{B}$; and at $54 \mathrm{~min}$ returns to initial conditions. The flow rate was $1 \mathrm{~mL} / \mathrm{min}$. Chromatograms were recorded at 280, 312, 360, and $520 \mathrm{~nm}$. Identification was based on the retention times and characteristic UV spectra and quantification was done by external standard curves.

\subsection{Statistical Analyses}

The results were analyzed by SPSS Statistics Program (21th version, IBM, New York, NY, USA) by using one way analysis of variance (ANOVA) at 0.05 significance level, and Tukey's New Multiple Range Test was applied for post hoc tests. The differences between all samples, PG, IN and OUT fractions were evaluated statistically. Tukey's Range Test was applied to exact values to observe the differences between TFC, TPC and TAC $(p<0.05)$. Each analysis was performed in triplicate and the results were reported as mean value \pm standard deviation.

\section{Conclusions}

From this work we conclude that a number of relevant antioxidant compounds that derive from the fruits are present in apple and grape vinegar. The initial results, including dedicated analytical methods and spectroscopic methods, indicate that the processing from fruit to vinegar has a strong effect on the presence of these compounds. This warrants a further study into the more global effects of processing. Also the in vitro digestion and bio-accessibility studies indicate that phenolic vinegar compounds undergo major reductions during food intake, indicating that there could be an interaction between vinegar processing and bio-accessibility. 
Acknowledgments: This study was financially supported by the Istanbul Technical University, Scientific Research Projects (BAP) Unit, and EU 7th Frame ATHENA Project (FP7-KBBE-2009-3-245121-ATHENA). We also thank to Mehmet Basri Çeliker and Kühne Co. (Kemalpaşa, İzmir, Turkey) for producing and supplying the samples.

Author Contributions: Sena Bakir, Gamze Toydemir, Dilek Boyacioglu and Esra Capanoglu conceived and designed the experiments; Sena Bakir and Gamze Toydemir performed the experiments; Sena Bakir, Esra Capanoglu, Gamze Toydemir and Jules Beekwilder analyzed the data; Sena Bakir, Gamze Toydemir, Esra Capanoglu and Jules Beekwilder wrote the paper.

Conflicts of Interest: The authors declare no conflict of interest. The founding sponsors had no role in the design of the study; in the collection, analyses, or interpretation of data; in the writing of the manuscript, and in the decision to publish the results.

\section{Abbreviations}

$\begin{array}{ll}\text { AJC } & \text { Apple Juice Concentrate } \\ \text { AW } & \text { Apple Wine } \\ \text { DAV } & \text { Decanted Apple Vinegar } \\ \text { DFAV } & \text { Decanted and filtered apple vinegar } \\ \text { DFGV } & \text { Decanted and filtered grape vinegar } \\ \text { DGV } & \text { Decanted Grape Vinegar } \\ \text { FAV } & \text { Final Apple Vinegar Product } \\ \text { FGV } & \text { Final Grape Vinegar Product } \\ \text { GW } & \text { Grape Wine } \\ \text { RGV } & \text { Raw Grape Vinegar } \\ \text { TAC } & \text { Total Antioxidant Capacity } \\ \text { TFC } & \text { Total Flavonoid Content } \\ \text { TPC } & \text { Total Phenolic Content } \\ \text { ABTS } & \text { 2,2'-azino-bis(3-ethylbenzothiazoline-6-sulphonic acid) } \\ \text { DPPH } & \text { 2,2-diphenyl-1-picrylhydrazyl } \\ \text { CUPRAC } & \text { Cupric reducing antioxidant capacity } \\ \text { Trolox } & \text { 6-hydroxy-2,5,7,8-tetramethylchroman-2-carboxylic acid } \\ \text { FRAP } & \text { Ferric reducing antioxidant power } \\ \text { TPTZ } & \text { Tripyridyl triazine } \\ \text { TEAC } & \text { Trolox equivalent antioxidant capacity } \\ \text { ANOVA } & \text { Analysis of variance }\end{array}$

\section{References}

1. Forbes-Hernández, T.Y.; Giampieri, F.; Gasparrini, M.; Mazzoni, L.; Quiles, J.L.; Alvarez-Suarez, J.M.; Battino, M. The effects of bioactive compounds from plant foods on mitochondrial function: A focus on apoptotic mechanisms. Food Chem. Toxicol. 2014, 68, 154-182. [CrossRef] [PubMed]

2. Giampieri, F.; Tulipani, S.; Alvarez-Suarez, J.M.; Quiles, J.L.; Mezzetti, B.; Battino, M. The strawberry: Composition, nutritional quality, and impact on human health. Nutrition 2012, 28, 9-19. [CrossRef] [PubMed]

3. Chiva-Blanch, G.; Visioli, F. Polyphenols and health: Moving beyond antioxidants. J. Berry Res. 2012, 2, 63-71.

4. Edirisinghe, I.; Burton-Freeman, B. Anti-diabetic actions of Berry polyphenols-Review on proposed mechanisms of action. J. Berry Res. 2016, 6, 237-250. [CrossRef]

5. Forbes-Hernandez, T.Y.; Gasparrini, M.; Afrin, S.; Bompadre, S.; Mezzetti, B.; Quiles, J.L.; Giampieri, F.; Battino, M. The healthy effects of strawberry polyphenols: Which strategy behind antioxidant capacity? Crit. Rev. Food Sci. Nutr. 2016, 56, S46-S59. [CrossRef] [PubMed]

6. Pistollato, F.; Giampieri, F.; Battino, M. The use of plant-derived bioactive compounds to target cancer stem cells and modulate tumor microenvironment. Food Chem. Toxicol. 2015, 75, 58-70. [CrossRef] [PubMed]

7. Giampieri, F.; Alvarez-Suarez, J.M.; Gasparrini, M.; Forbes-Hernandez, T.Y.; Afrin, S.; Bompadre, S.; Rubini, C.; Zizzi, A.; Astolfi, P.; Santos-Buelga, C.; et al. Strawberry consumption alleviates doxorubicin-induced toxicity by suppressing oxidative stress. Food Chem. Toxicol. 2016, 94, 128-137. [CrossRef] [PubMed]

8. Shahidi, F.; Naczk, M. Food Phenolics: Sources, Chemistry, Effects and Applications; Technomic Publishing Co.: Lancaster, PA, USA, 1995.

9. Devasagayam, T.P.A.; Tilak, J.C.; Boloor, K.K.; Sane, K.S.; Ghaskadbi, S.; Lele, R.D. Free radicals and antioxidants in human health: Current status and future prospects. J. Assoc. Physicians India 2004, 52, 794-804. [PubMed] 
10. Slaga, T.J.; O'Connell, J.; Rotstein, J.; Patskan, G.; Morris, R.; Aldaz, M.; Conti, C.J. Critical genetic determinants and molecular events in multistage skin carcinogenesis. Symp. Fundam. Cancer Res. 1987, 39, 31-34.

11. Marnett, L.J. Oxyradicals and DNA damage. Carcinogenesis 2000, 21, 361-370. [CrossRef] [PubMed]

12. Scalbert, A.; Williamson, G. Dietary intake and bioavailability of polyphenols. J. Nutr. 2000, 130, 2073S-2085S. [PubMed]

13. Manach, C.; Williamson, G.; Morand, C.; Scalbert, A.; Rémésy, C. Bioavailability and bioefficacy of polyphenols in humans. I. Review of 97 bioavailability studies. Am. J. Clin. Nutr. 2005, 81, 230S-242S. [PubMed]

14. Williamson, G.; Manach, C. Bioavailability and bioefficacy of polyphenols in humans. II. Review of 93 intervention studies. Am. J. Clin. Nutr. 2005, 81, 243S-255S. [PubMed]

15. Lau, F.C.; Shukitt-Hale, B.; Joseph, J.A. Beneficial effects of berry fruit polyphenols on neuronal and behavioral aging. J. Sci. Food Agric. 2006, 86, 2251-2255. [CrossRef]

16. Jimenez, P.; Arranz, S.; Tabernero, M. Updated methodology to determine antioxidant capacity in plant foods, oils and beverages: Extraction, measurement and expression of results. Food Res. Int. 2008, 41, $274-285$. [CrossRef]

17. Capanoglu, E.; Beekwilder, J.; Boyacıoglu, D.; Hall, R.; Vos, R.D. Changes in antioxidant and metabolite profiles during production of tomato paste. J. Agric. Food Chem. 2008, 56, 964-973. [CrossRef] [PubMed]

18. Capanoglu, E.; de Vos, R.C.; Hall, R.D.; Boyacioglu, D.; Beekwilder, J. Changes in polyphenol content during production of grape juice concentrate. Food Chem. 2013, 139, 521-526. [CrossRef] [PubMed]

19. Kamiloglu, S.; Capanoglu, E. In vitro gastrointestinal digestion of polyphenols from different molasses (pekmez) and leather (pestil) varieties. Int. J. Food Sci. Technol. 2013, 49, 1027-1039. [CrossRef]

20. Toydemir, G.; Capanoglu, E.; Gomez-Roldan, M.V.; de Vos, R.C.H.; Boyacioglu, D.; Hall, R.D.; Beekwilder, J. Industrial processing effects on phenolic compounds in sour cherry (Prunus cerasus L.) fruit. Food Res. Int. 2013, 53, 218-225. [CrossRef]

21. Toydemir, G.; Capanoglu, E.; Kamiloglu, S.; Boyacioglu, D.; de Vos, R.C.H.; Hall, R.D.; Beekwilder, J. Changes in sour cherry (Prunus cerasus L.) antioxidants during nectar processing and in vitro gastrointestinal digestion. J. Funct. Foods 2013, 5, 1402-1413. [CrossRef]

22. Giampieri, F.; Alvarez-Suarez, J.M.; Mazzoni, L.; Forbes-Hernandez, T.Y.; Gasparrini, M.; Gonzàlez-Paramàs, A.M.; Santos-Buelga, C.; Quiles, J.L.; Bompadre, S.; Mezzetti, B.; et al. An anthocyanın-rich strawberry extract protects against oxidative stress damage and improves mitochondrial functionality in human dermal fibroblasts exposed to an oxidizing agent. Food Funct. 2014, 5, 1939-1948. [CrossRef] [PubMed]

23. Fushimi, T.; Tayama, K.; Fukaya, M.; Kitakoshi, K.; Nakai, N.; Tsukamoto, Y. Acetic acid feeding enhances glycogen repletion in liver and skeletal muscle of rats. J. Nutr. 2001, 131, 1973-1977. [PubMed]

24. Qui, J.; Ren, C.; Fan, J.; Li, Z. Antioxidant activities of aged oat vinegar in vitro and in mouse serum and liver. J. Sci. Food Agric. 2010, 90, 1951-1958.

25. Natera, R.; Castro, R.; Valme-Garcia-Moreno, M.D.; Hernandez, M.J.; Garcia-Barroso, C. Chemometric studies of vinegars from different raw materials and processes of production. J. Agric. Food Chem. 2003, 51, 3345-3351. [CrossRef] [PubMed]

26. Alonso, A.M.; Castro, R.; Rodriguez, M.C.; Guillen, D.A.; Barroso, C.G. Study of the antioxidant power of brandies and vinegars derived from Sherry wines and correlation with their content in polyphenols. Food Res. Int. 2004, 37, 715-721. [CrossRef]

27. McDougall, G.J.; Dobson, P.; Smith, P.; Blake, A.; Stewart, D. Assessing potential bioavailability of raspberry anthocyanins using an in vitro digestion system. J. Agric. Food Chem. 2005, 53, 5896-5904. [CrossRef] [PubMed]

28. Frankel, E.N.; Meyer, A.S. The problems of using one-dimensional methods to evaluate multifunctional food and biological antioxidants. J. Sci. Food Agric. 2000, 80, 1925-1941. [CrossRef]

29. Niki, E. Antioxidant capacity: Which capacity and how to assess it? J. Berry Res. 2011, 1, 169-176.

30. Verhoef, S.; Ruijssenaars, H.J.; de Bont, J.A.; Wery, J. Bioproduction of $p$-hydroxybenzoate from renewable feedstock by solvent-tolerant Pseudomonas putida S12. J. Biotechnol. 2007, 132, 49-56. [CrossRef] [PubMed]

31. Davalos, A.; Bartolome, B.; Gomez-Cordoves, C. Antioxidant properties of commercial grape juices and vinegars. Food Chem. 2005, 93, 325-330. [CrossRef] 
32. Masino, F.; Chinnici, F.; Bendini, A.; Montevecchi, G.; Antonelli, A. A study on relationships among chemical, physical, and qualitative assessment in traditional balsamic vinegar. Food Chem. 2008, 106, 90-95. [CrossRef]

33. Cejudo-Bastante, M.J.; Durán Guerrero, E.; Castro Mejías, R.; Natera Marín, R.; Rodríguez Dodero, M.C.; García Barroso, C. Study of the polyphenolic composition and antioxidant activity of new Sherry vinegar-derived products by maceration with fruits. J. Agric. Food Chem. 2010, 58, 11814-11820. [CrossRef] [PubMed]

34. Ubeda, C.; Hidalgo, C.; Torija, M.J.; Mas, A.; Troncoso, A.M.; Morales, M.L. Evaluation of antioxidant activity and total phenols index in persimmon vinegars produced by different processes. Food Sci. Technol. 2011, 44, 1591-1596. [CrossRef]

35. Cerezo, A.B.; Tesfaye, W.; Soria-Diáz, M.E.; Torija, M.J.; Mateo, E.; Garcia-Parrilla, M.C.; Troncoso, A.M. Effect of wood on the phenolic profile and sensory properties of wine vinegars during ageing. J. Food Comp. Anal. 2010, 23, 175-184. [CrossRef]

36. Toydemir, G.; Boyacioglu, D.; Capanoglu, E.; van der Meer, I.M.; Tomassen, M.M.; Hall, R.D.; Mes, J.J.; Beekwilder, J. Investigating the transport dynamics of anthocyanins from unprocessed fruit and processed fruit juice from sour cherry (Prunus cerasus L.) across intestinal epithelial cells. J. Agric. Food Chem. 2013, 61, 11434-11441. [CrossRef] [PubMed]

37. Kamiloglu, K.; Boyacioglu, D.; Capanoglu, E. The effect of food processing on bioavailability of tomato antioxidants. J. Berry Res. 2013, 3, 65-77.

38. Spanos, G.A.; Wrolstad, R.E. Influence of processing and storage on the phenolic composition of thompson seedless grape juice. J. Agric. Food Chem. 1990, 38, 1565-1571. [CrossRef]

39. Dewanto, V.; Wu, X.; Adom, K.K.; Liu, R.H. Thermal processing enhances the nutritional value of tomatoes by increasing total antioxidant activity. J. Agric. Food Chem. 2002, 50, 3010-3014. [CrossRef] [PubMed]

40. Miller, N.J.; Rice-Evans, C.A. Factors influencing the antioxidant activity determined by the ABTS $\bullet^{+}$radical cation assay. Free Radic. Res. 1997, 26, 195-199. [CrossRef] [PubMed]

41. Kumaran, A.; Karunakaran, R.J. Antioxidant and free radical scavenging activity of an aqueous extract of Coleus aromaticus. Food Chem. 2006, 97, 109-114. [CrossRef]

42. Apak, R.; Güçlü, K.; Özyürek, M.; Karademir, S.E. Novel total antioxidant capacity index for dietary polyphenols and vitamins $\mathrm{C}$ and $\mathrm{E}$, using their cupric ion reducing capability in the presence of neocuproine: CUPRAC method. J. Agric. Food Chem. 2004, 52, 7970-7981. [CrossRef] [PubMed]

43. Benzıe, I.F.F.; Strain, J.J. The ferric reducing ability of plasma (FRAP) as a measure of "antioxidant power": The FRAP assay. Anal. Biochem. 1996, 239, 70-76. [CrossRef] [PubMed]

44. Sagdic, O.; Ozturk, I.; Ozkan, G.; Yetim, H.; Ekici, L.; Yilmaz, M.T. RP-HPLC-DAD analysis of phenolic compounds in pomace extracts from five grape cultivars: Valuation of their antioxidant, antiradical and antifungal activities in orange and apple juices. Food Chem. 2011, 126, 1749-1758. [CrossRef] [PubMed]

45. Que, F.; Mao, L.; Pan, X. Antioxidant activities of five Chinese rice wines and the involvement of phenolic compounds. Food Res. Int. 2006, 39, 581-587. [CrossRef]

46. Matejıcek, D.; Mikes, O.; Klejdus, B.; Sterbova, D.; Kuban, V. Changes in contents of phenolic compounds during maturing of barrique red wines. Food Chem. 2005, 90, 791-800. [CrossRef]

47. Samanidou, V.F.; Antoniou, C.V.; Papadoyannis, I.N. Gradient RP-HPLC determinaiın of free phenolic acids in wines and wine vinegar samples after SPE, with photodiode array identification. J. Liq. Chromatogr. Relat. Technol. 2001, 24, 2161-2176. [CrossRef]

(c) 2016 by the authors; licensee MDPI, Basel, Switzerland. This article is an open access article distributed under the terms and conditions of the Creative Commons Attribution (CC-BY) license (http://creativecommons.org/licenses/by/4.0/). 